\title{
Organisation of Independent Work of Students of a Technical University in Field-Specific Disciplines: Instructional Commitment of a Lecturer
}

\author{
Lyudmila A. Redko \\ Assistant professor, PhD, National Research Tomsk Polytechnic University, Russia; E-mail: laredko@tpu.ru \\ Lyudmila A. Sivitskaya \\ Assistant professor, PhD, National Research Tomsk Polytechnic University, Russia; E-mail: sivitskaya@tpu.ru \\ Evgeniya O. Frantsuzskaya
}

Senior teacher, National Research Tomsk Polytechnic University, Russia; E-mail: francuzskaya@tpu.ru

Marina N. Yanushevskaya

Senior teacher, National Research Tomsk Polytechnic University, Russia; E-mail: yanushevskaj@tpu.ru

Doi:10.5901/mjss.2015.v6n6s1p142

\section{Abstract}

\begin{abstract}
The competency-based approach is regarded as the basic approach in higher educational institutions nowadays. The approach suggests certain requirements for both university lecturers and students as active participants of the teaching and learning process. In terms of the competency-based approach the development of students' autonomy and the pedagogical conditions which stimulate and maintain the autonomy are supposed to be crucial. The paper analyses the results of the survey focused on the instructional commitment of graduate department lecturers to organise independent work of students. Students' independent work is viewed as the most essential cognitive activity which involves certain content and organisational challenges for both students and lecturers. The survey resulted in identification of the principle directions of development of pedagogical conditions of students' independent work organisation in the process of learning in the framework of field-specific disciplines which are delivered by the Department of Physical Methods of Non-Destructive Testing of National Research Tomsk Polytechnic University, Russia.
\end{abstract}

Keywords: students' independent work, technical university, pedagogical conditions, instructional commitment of the lecturer

\section{Introduction}

Nowadays the category of competency is often used for staff professionalism evaluation. Competency is defined as a characteristic of a subject of activity which reflects their ability and commitment to perform professional tasks. Meanwhile competency is as a goal of professional education leads to some structural changes in approaches to the teaching and learning process. The strategy of this modernisation is the introduction of the competency-based approach which defines the field-specific direction of educational programmes in the higher school (Smyshlyaeva, 2010). Higher education itself becomes a tool to form the basis for the future efficient and successful activity which underlies the competitiveness of a modern specialist in the labour market.

Evidently, professionalism of higher school staff serves as the most important factor of the innovation development of education (Sivitskaya, 2010). In accordance with the concepts of the competency-based approach the classical educational traditions cross over to a new education, which is connected with the creative development of a personality. The role of the student changes so that they become an active subject of the educational process. The changes can only be supported with a specific culture of pedagogical mentality which is characterised by acmeological and empathical conditions, dialogueness, reflexivity and creativity. The new features affect the appearance of new approaches to organisational and activity components of the educational process.

The competency-based approach suggests higher motivation of students, responsibility for their learning outcomes, self-education and self-development. Implementing the approach leads to certain changes from formal 
knowledge transition to creation of educational conditions for self-education in accordance with an individually chosen trajectory and educational environment focused on an individual. In terms of this approach the core activity of a student is their independent work. The main goal of the organization of students' independent work in the university is mastering skills in solving field-specific tasks applying the theoretical practical knowledge acquired earlier and receiving essential professional competences.

Students' independent work is further subdivided into classroom independent work, out of class independent work and self-guided work.

Classroom independent work is performed in class, initiated, organized and assessed by the lecturer. Out of class independent work is the work organized by a student as assigned by the lecturer according to the planned learning outcomes. Self-guided independent work is performed by the student by their own initiative outside the classroom (Regulation of Organisation of Students' Independent Work..., 2015).

Independent work is an essential part of the educational process which is planned, coordinated and assessed by the lecturer. Thus the quality of the lecturer performance affects greatly the outcomes of the educational process. Students' independent work should be supported with a well developed infrastructure which is the governmental requirement to the core activity of a higher educational establishment (Order of Ministry of Education and Science..., 2014). In other words the educational process in the higher educational establishment and students' independent work as its part can be successfully organized in case of creating a certain system of conditions which can also be called pedagogical conditions (Kovaleva, 2014). These include motivation of students to self-guided activity (George, 2011) which includes both the needs and commitment of students for self-development, as well as conditions of student-lecturer communication; university infrastructure and methodical literacy of the lecturer.

Methodical literacy of the lecturer is an essential part of the general competency and "didactic competency" of the lecturer (Tyrina, 2012). A careful preparation is required to perform any methodical work [8]. In terms of realization of the competency-based approach methodical work of the lecturer possesses a substantial strategic component in order to form competencies in conditions of the discipline being delivered (Osjkina, 2013; Bukhmin, 2015) though it turns out to be very time-consuming. Nowadays the methodical literacy of the lecturer is characteristic of the following skills: the choice of field-oriented tasks for students' independent work matching interests and the level of students' educational background, designing algorithms of fulfillment and assessment of performing those tasks.

Nowadays the educational process in the National Research Tomsk Polytechnic University, Russia, is organized according to the requirements of the competency-based approach and developing a personality-developing environment in terms of core educational programmes. A core educational programme is a set of teaching and learning materials, learning goals and outcomes, indicators and methods of assessment, contents and delivery of the programme in terms of a certain profile and direction of training as well as the level of training (Abrashkina, 2012). In the process students study modules of disciplines: humanitarian, social and economic, science and mathematical as well as professional. As the delivery of professional modules of disciplines is provided by the university departments, the pedagogical conditions are supposed to be of high importance as they define the quality of students' learning and meeting the requirements of employers and those who may concern the quality of students' education (state government, students, university itself).

\section{Goal and Objectives of the Survey "Study of Pedagogical Conditions of Students' Independent Work Organisation in Terms of Instructional Commitment of a Lecturer"}

Tomsk Polytechnic University (TPU) as one of leading universities in the Russian Federation has recently been awarded the status of "National Research University" and sets as a strategic goal "to become one of the world-leading research universities in the area of resource-efficient technologies solving global societal, economic and environmental problems for the benefit of the mankind sustainable development" (Chubik, 2013, 2015).

The Strategic Programme of National Research Tomsk Polytechnic University Competitiveness Enhancement in the Group of Top Level World Research and Academic Institutions (TPU Strategic Programme) for 2013-2020 presents the steps to be made to contribute substantially to increasing TPU competitiveness in Russia and its standing in world university rankings.

Facing the ambitious plans to become one of the top leading universities the university has started structural changes in all spheres of its organization. In terms of the educational process organization there has taken place some redistribution of the workload of lecturers. To increase effectiveness and promote autonomy of students the amount of hours devoted to students' independent work has expanded.

To study the existing pedagogical conditions of students' independent work the survey of students and lecturers was delivered. The survey covered the professional activity of one university department. Totally about a hundred 
students and all the staff members of the department were surveyed.

The questionnaire which the participants were provided with consisted of the following sections:

I. Motivation of students to perform independent work;

II. Pedagogical technologies and forms of students' independent work organisation;

III. Students' independent work courseware;

IV. University business communication culture;

V. Students' independent work infrastructure in the university.

The goal of the work was to reveal the main directions of development of pedagogical conditions of the university department. The survey aspired increasing the methodical literacy of the lecturer who is responsible for students' independent work organisation.

To achieve the set goal the work tended to deal with the following tasks:

- Define and classify students' independent work;

- Analyse the dynamics of the amount of students' independent work for the recent years;

- Analyse the dynamics of the amount of lecturers work hours which was focused on the methodical work;

- Study the state of pedagogical conditions.

The following methods of research were used: literature source analysis; the survey itself; statistical analysis of the data received; discussion.

\section{Research Timeliness}

For the period from 2012 to 2014 National Research Tomsk Polytechnic University experienced a certain increase of hours for students' independent work in terms of field-specific disciplines. Here is the analysis of hours which have been provided in the curriculum for the period from 2012 up to present:

In the curriculum of 2012 students' independent work made up about 54,2\% of the total hours; in 2013 and 2014 the percentage remained the same at the level of $59,6 \%$, which is insignificantly higher than previously; in 2015 the number of hours for independent work has slightly increased to $59,8 \%$.

Thus it can be concluded that the quality of the educational process is defined by the quality of the organization of students' independent work in general.

The recent changes have affected the structure of workload distribution of the lecturer. The number of hours to be devoted to research has increased meanwhile the methodical workload hours have significantly declined. Here is seen a strong tendency to reduce the amount of methodical workload performed by the lecturer. So that in 2012 the methodical workload made up $36 \%$ of the whole workload; later in 2013 it decreased to $30 \%$ and in 2014 it finally appeared at $10 \%$ of the total amount of workload.

A proper organisation of students' independent work generally appears highly time-consuming. Students' independent work is a consolidated effort of both students and lecturers which can be represented with a simple PDCA (plan-do-check-act) model. The four stages of the model can be used to explain the specificity of the students' independent work organisation.

\subsection{PDCA Stage 1: Planning}

This stage of the PDCA (plan-do-check-act) model requires the comprehension of the resultative independent work of students, which methods can be used to achieve the results and how the result can be evaluated and analysed

The stages covers the following important steps:

- Instructing lecturers how to organise the students' independent work effectively;

- Setting goals and objectives of students' independent work, differentiating its levels of difficulty (basic and advanced levels);

- Needs analysis for the resources involved (time, sources of information, software, equipment);

- Setting criteria and methods of assessment of the independent work results;

- Defining forms and work schemes and schedules for student-lecturer interaction in terms of independent work.

\subsection{PDCA Stage 2: Performing}

The stage for the students' activity when they perform their independent work. Students' activity can include: 
- Information source analysis; defining the problem and its importance; defining methods of solving tasks and all the necessary steps that are necessary to achieve the results;

- Solving students' independent work tasks;

- Making reports and preparing the documentation on the results of the independent work;

- Preparing an oral presentation on the results of the independent work. The lecturer coordinates the student activity.

\subsection{PDCA Stage 3: Assessment}

Student presentation of the results of the independent work takes place at this stage.

Cumulative assessment is provided including: self-assessment, peer assessment and assessment from the lecturer.

\subsection{PDCA Stage 4: Feedback}

The results of students' independent work are discussed and reflected on in the form of seminars and on-line forums. Feedback is provided by both the lecturers and students.

The contents of the stages of the students' independent work made us conclude that the most important part of its delivery is the stage of planning where the methodical literacy of a lecturer allows setting the tasks to students according to their interests, level of educational background, algorithms of the task performance, lists of information sources and structures of the work assessment.

\section{Present Conditions of Students' Independent Work in the Department of Physical Methods of Non- destructive Testing}

At present the university staff members do a lot to increase the quality of educational process results and match those to the requirement of employers. The organisation of students' independent work has changed in terms of curricula so that there appeared such new disciplines to be taught and studied as "Creative Project", research and development work of students, placements and internships of all kinds.

The infrastructure of the university in general matches all the requirements for the educational process. National Tomsk Polytechnic University provides lecturers and students with all the necessary equipment, software and information sources. The university scientific and technical library provides the on-line access to $70-80$ full text and bibliographical data bases. Electronic educational resources are actively designed and developed in the university.

All the lecturers have their personal web pages where they can publish the necessary information on the courses they deliver. All the students have access to electronic library and social catalogues to get updated information on research, cultural and educational events to from their portfolio of achievements.

Most lecturers apply various pedagogical technologies of students' cognition activation such as: case study, projects, games and some others (Redjko, 2014). However, this mostly refers to students' classroom lecturer supervised independent work. Considering out of class independent student work, here the university has performed different actions in order to systematize and link the existing resources into a laconic scheme which is regulated by the University Policy about Students' Independent Work (Regulation of Organisation of Students' Independent Work..., 2015). The department can take some tactic steps to put into practice those strategic directions of students' out of class independent work.

Here the study results of the pedagogical conditions of the department under study are described in terms of the organisation of students' independent work.

\section{Present Conditions of Students' Independent Work in the Department}

To study the pedagogical conditions of organisation of students' independent work a survey was held among the department teaching staff and students. The total number of participants was about a hundred students including bachelor and master degree students. The teaching staff of the department also participated in total number of 11 members.

The questionnaire included several sections such as

I. Motivation of students to perform independent work; 
II. Pedagogical technologies and forms of students' independent work organisation;

III. Students' independent work courseware;

IV. University business communication culture;

V. Students' independent work infrastructure in the university.

Here are the results of the survey analysis described.

\subsection{Motivation of students to perform independent work}

In general students can understand the importance and meaning of students' independent work in their education and are quite positive about this type of activity as the one providing them with opportunities for further development. Students do understand the objectives set for them by the lecturer and perform the set tasks in the due of the semester study. On the other hand, skills of self management such as prioritizing, effective time planning, taking on responsibilities have to be further developed with at least half of the students surveyed. Most students believe that they can at least set a goal by themselves.

The lecturers reckon that the students understand how important the independent work is for their education but they are not motivated well enough to perform this kind of work. The level of students' self management skills was estimated as an average one. The skills to be developed for the successful independent work performance are information search, its analysis and conclusion, self discipline and critical thinking. As these essential skills actually underline the motivation to study in general and perform independent work, for instance.

\subsection{Performing pedagogical technologies and forms of students' independent work organisation}

From the students' point of view, the two most popular types of students' independent work are doing home work and submitting tasks in the electronic environment. They do find doing homework quite effective in terms of their study. Approximately one third of all master students also mentioned "research" as a popular type of students' independent work. The students never mentioned such forms as reading professional literature, doing research on the topic chosen and working on the project as ordered by a company.

The results indicate a group of students with higher demands for the educational process, so that more difficult tasks and research objectives can be set for them.

The student expressed their opinion that they are to be taught how to perform independent work by the lecturer. About one third of students are ready to study from each other, but it can be considered that the number of the latter is higher.

From the point of view of most students, their independent work is to be assessed by the lecturer. Though fist year students and master degree students would prefer to assess their work mostly by themselves while second and third year students suggest peer assessment of the independent work.

These opinions indicate the unwillingness of student to take responsibility for their independent work which suggests that lecturers should provide students with clear criteria of cumulative assessment including lecturer's evaluation, self and peer assessment. Reflective thinking should be developed for better result analysis.

Among the most effective forms of students' independent work the lecturers surveyed list the common widespread forms such as doing homework, their course papers as well as such rarely used forms of project work through the request of an external employer. The lecturers surveyed mostly listed such forms of students' independent work that are often used in the professional practice: individual homework, reports, course papers, essays and some other types which unfortunately can be a sign of insufficient methodical literacy of the lecturer. Field-oriented tasks are quite seldom used as there could be some coordination problems in recruiting external companies to participate in the student project work.

In lecturers' opinion, the most preferable forms of independent work assessment are lecturer evaluation and peer student evaluation. The lecturers surveyed underestimate the importance of student self assessment of their independent work.

\subsection{Students' independent work courseware}

The lecturers surveyed believe that sufficient courseware allows increasing students' independent work efficiency though they find it quite complicated to get the proper materials ready for the course. As implementation of new teaching technologies provides the lecturer with new tools to optimise their professional activity and the majority are ready to get new didactic skills. 


\subsection{University business communication culture}

The lecturers surveyed mostly admit a positive communication environment for student-lecturer interaction.

Views on the role of the lecturer in the process of organization of students' independent work widely vary. Most of the lecturers who participated in the survey identify their role as that of an organiser, consultant, expert or coordinator, though about $5 \%$ of the lecturers still consider the process of transition of knowledge to students.

\subsection{Students' independent work infrastructure in the university}

The infrastructure for the organisation of student's independent work requires providing students with sources of information for efficient study. Though the university library can easily meet any students' demands they still prefer using the Internet as they primary source of information. Students are not in the habit of working in the library and often lack skills of information search. As the competency in information search grows more students get engaged into reading and the range of the information sources expands. skills.

As the survey results show the students demand for being taught how to develop their reading and critical reading

In general, both students and lecturers are to be provided with methodical support for their work in organisation and performing independent work.

\section{Recommendations on Increasing Methodical Literacy of Lecturers}

The survey resulted in designing and developing some recommendations to increase the methodical literacy of lecturers in terms of organization of students' independent work. At different levels of staff members in the department can contribute to the organization of students' independent work in several ways.

\subsection{Motivation}

The staff member responsible for the organization of the learning process in the department can coordinate:

- Providing the teaching staff with updated information through seminars and electronic resources;

- Awarding the most talented teaching staff members for their teaching achievements and transfer their teaching experience.

- Preventing teaching staff member from professional burning out.

The department teaching staff members can in their turn work directly with their students covering such challenging issues as:

- The principle methods of information search and process;

- Developing students' skills of critical thinking;

- Developing autonomy and responsibility of students

- Differentiating the difficulty level of objectives and tasks taking into consideration students' talents, wishes and abilities.

\subsection{Teaching technologies and forms of students' independent work organization}

The responsibilities of the learning process coordinator can include:

- Enhancement teaching staff members' skills in terms of implementation of modern teaching technologies into their practice. The focus is supposed to be on the skills of organization students' independent work as the essential part of the teaching process.

- Development of virtual learning environment which can actively be used as a web support of any face-to-face course;

- Transfer face-to-face staff meetings into electronic environment as the most effective form of professional communication which can easier be implemented into the tense workload of teaching staff members.

- Development of interdisciplinary links to engage students into projects and studying selected issues through the medium of various disciplines.

Teaching staff members can improve the existing learning setting by 
- Implementing various teaching technologies into the learning process to vary the types of activity;

- Focusing on field-specific tasks for students to increase their motivation;

- Differentiating tasks according to the levels of complexity;

- Changing the role of a lecturer in the learning process, providing students with effective and productive feedback after cumulative assessment analysis.

\subsection{Methodical support of students' independent work}

The staff member responsible for the coordination of the learning process in the department can develop a chart of students' independent work which represents the notion of independent work in terms of forms, types, methods and technologies to be used as it can be seen from Table 1 (Altschuller, 2015).

Table 1. Structure of students' independent work

\begin{tabular}{|c|c|c|c|c|}
\hline Independent work objectives & $\begin{array}{l}\text { Assimilating the studied } \\
\text { material }\end{array}$ & $\begin{array}{l}\text { Proactive students' } \\
\text { independent work }\end{array}$ & $\begin{array}{l}\text { Creative abilities } \\
\text { development }\end{array}$ & Critical thinking development \\
\hline Type of independent work & creative & researching & theoretical review & practice \\
\hline Time for submitting & one week & two weeks & four weeks & one semester \\
\hline Students' learning background & adequate & average & higher than average & \\
\hline Number of students in the group & 1 & 2 & 3 & 5 \\
\hline Type of assessment & self assessment & peer assessment & lecturer assessment & cumulative assessment \\
\hline Complexity level & basic & advanced & & \\
\hline Information sources & internet & periodical issues & books & theses, monographs \\
\hline Functions in the learning process & $\begin{array}{l}\text { focused on the discipline } \\
\text { content assimilation }\end{array}$ & $\begin{array}{l}\text { considers interdisciplinary } \\
\text { connections in the scope } \\
\text { of field-specific disciplines } \\
\text { of the degree programme }\end{array}$ & \begin{tabular}{|l|} 
analyses \\
interdisciplinary links \\
among field-specific \\
and general study \\
subjects \\
\end{tabular} & $\begin{array}{l}\text { logically connects all the } \\
\text { knowledge, skills and } \\
\text { experience obtained earlier }\end{array}$ \\
\hline $\begin{array}{l}\text { Presentation form of } \\
\text { independent work }\end{array}$ & $\begin{array}{l}\text { a printed paper: report, essay, } \\
\text { test, placement / internship } \\
\text { report, research paper }\end{array}$ & $\begin{array}{l}\text { report submitted } \\
\text { electronically }\end{array}$ & $\begin{array}{l}\text { report and oral } \\
\text { presentation }\end{array}$ & $\begin{array}{l}\text { creative form: a video } \\
\text { fragment, a tabletop game, a } \\
\text { puzzle game and other types }\end{array}$ \\
\hline
\end{tabular}

- Working out recommendations containing types and forms of students' independent work, deadlines for submission (Izmaylova, 2009)

- Developing typical criteria for assessment of the independent work results.

Teaching staff members can contribute by:

- Using various types of tasks and ways of result presentation;

- Promoting tasks promoting students' team work;

- Using peer assessment of students' work;

- Providing productive feedback after cumulative assessment analysis.

\subsection{Culture of business communication}

The staff member responsible for learning process coordination can :

- Plan events such as trainings, seminars, focusing on shaping skills of subject-subject interaction;

- Foster the atmosphere of trust and respect though the unity of aims: high quality of students' training, professional enhancement of lecturers, support for opinion share and approaches to organization of the learning process.

Teaching staff can:

- Inform students about possible ways of communication while learning;

- Maintain contact with students within the academic term.

\subsection{Infrastructure of students' work organisation}

The possible recommendations for the specialist for the learning process coordination include:

- Needs analysis in courseware, electronic bases, computer software and equipment; 
- Design algorithms for information processing for students' independent work;

- Share best practices of organization of students' independent work with lecturers.

Teaching staff members can take the responsibility for:

- Teaching students how to search information in different information sources and process it;

- Developing students' skills of critical thinking through reading and writing;

- Analyzing sources of information which students use for their independent work.

These recommendations can be implemented into teaching practice and further results can be shared with staff members of the same department. To share the results and experience various methods can be used such as selfevaluation, meetings, peer-evaluation and some others (Collinson, 2006).

\section{Conclusion}

Challenges of competency-based approach realization can be listed as such:

- Engaging students into the learning process;

- Making students take the responsibility for the results of their study;

- Teaching lecturers how to give classes with regard to competency-based approach and subject-subject interaction;

- Developing infrastructure for realization of learner-centered approach in teaching and learning.

The authors consider the systematic approach to designing appropriate pedagogical conditions to be the most important thing in methodical support of lecturers who provide the organization of students' independent work as the way to achieve high results. The approach takes into consideration the unity in understanding the aims and objectives of the importance of students' independent work by all the subjects of the learning process, identifying the required resources, the algorithm of organization of students' independent work as a process, the role of a lecturer in the process and the student-lecturer interaction.

The specific recommendations can be suggested covering the following list:

- Teaching lectures how to set objectives and choose the most effective forms of students' independent work;

- Developing methodical support as well as ways of interaction with students both face-to-face and in the electronic environment and methods of assessment.

The increase the effectiveness of lecturers' performance some regulations can be developed to cover: recommendations on the ratio of students' interdependent work forms and time limits for submitting the assignments, forms of teaching support of the independent work; forms of result presentation, methods of assessment with well described criteria and methods of information search and processing. These regulation papers can be used as a start point for designing students' independent work in terms of one discipline, one year of study or the whole degree programme.

\section{Acknowledgement}

The presented work and the current paper are funded within the framework of realization of Strategic Programme on National Research Tomsk Polytechnic University Competitiveness Enhancement in the Group of Top Level World Class Research and Academic Institutions.

\section{References}

Smyshlyaeva, L., Sivitskaya, L. (2010). Pedagogical Technologies of Activation of Instruction in Higher School. Text book. Tomsk Polytechnic University.

Sivitskaya, L., Smyshlyaeva, L. (2010). Technological Background for Development of Professional Competences of the Higher School Lecturer. Text book. National Research Tomsk Polytechnic University.

Regulation of Organisation of Students' Independent Work in Tomsk Polytechnic University, approved by Rector's Order 33 dated 17.03.2015.

Order of Ministry of Education and Science of Russia dated 30.10.2014 N 1401 "On Approving the Federal State Educational Standard of Higher Education on the Direction of Training 27.04.02 Quality Management (Master Degree)". Registered in the Ministry of Justice of the Russian Federation 26.11.2014 N 34945). ConsultantPlus, www.consultant.ru.

Kovaleva, N. (2014). Pedagogical Conditions of Forming Research Competency of Students in a Teacher Training College. Innovative Development of Professional Education 1(05), 49-55. 
George, I. (2011).Psychological and Pedagogical Conditions of Preparation Students for Independent Work. Higher Education Today 8, 42-43.

Tyrina, M. (2012) Didactic Competency of a Lecturer and its Development. The News of Altai State University 2-1, 36-40.

Osjkina, M. (2013) Development Lecturer's Commitment to Methodical Work in the System of Advanced Training. Discussion, 158-162.

Bukhmin, V., Chitalin, N. (2015). Project and Methodical Activity of a Lecturer Focused on Competences Development. Engineering Pedagogy. Moscow State Automobile and Road Technical University Moscow 17 (1), 69-76.

Abrashkina, I., Boev, O., Vronova, G., Epikhin, A. and others. (2012).Standards and Regulations on Providing the Quality of Core Educational Programmes of Training Bachelors, Masters and Specialists on Priority Development Directions of national Research Tomsk Polytechnic University (Standard for Core Educational Programmes of TPU). Reference book on Standard Materials. Edition 4.Tomsk Polytechnic University, 206 p.

Chubik, P. (2013, 2015). Strategic Programme of National Research Tomsk Polytechnic University Competitiveness Enhancement in the Group of Top Level World Research and Academic Institutions, 4-30.

Redjko, L., Plotnikova, I. (2014). Experience of Organisation of Teaching Quality Management. Standards and Quality 1, 68-73.

Altschuller, G. (2015) Find an Idea. Introduction to the Theory of Inventive Problem Solving. Moscow.

Izmaylova, M.(2009). Organisation of out of Class Independent Work of Students. Text book. Moscow.

Collinson, Ch., Parcell, G. (2006). Learning to Fly: Practical Knowledge Management from Leading and Learning Organizations. Institute for Integral Strategic Research. 